\title{
REVIEW ON THE POSSIBLE TOOL MATERIALS FOR FRICTION STIR WELDING OF STEEL PLATES
}

\author{
Sierens A. ${ }^{1}$, Vanvooren J. ${ }^{1}$, Deplus K. ${ }^{2}$, Faes K. ${ }^{2}$, De Waele W. ${ }^{3}$ \\ ${ }^{1}$ Ghent University, Belgium \\ ${ }^{2}$ Belgian Welding Institute, Belgium \\ ${ }^{3}$ Ghent University, Laboratory Soete, Belgium
}

\begin{abstract}
The friction stir welding (FSW) process is mainly used in industrial applications for joining low melting temperature materials such as aluminium and magnesium. FSW has many advantages in comparison with conventional fusion arc welding. Therefore the interest to use this technique for joining steel plates has grown. However such usage is still limited because of the lack of adequate tool materials. This review gives an overview of possible tool materials for FSW of steels focussing on tungsten, tungsten carbide, pcBN and a few ultra-high temperature ceramics.
\end{abstract}

Keywords: FSW, tool material, steel plates

\section{INTRODUCTION}

Friction stir welding has in comparison with conventional fusion arc welding many metallurgical, environmental and energetic advantages [1]. There are also less process parameters to control which facilitates its use. This solid state joining process is implemented in industrial applications for materials with low melting temperatures such as aluminium and magnesium alloys [2, 3]. However, the development of friction stir welding of steel has progressed more slowly due to the higher temperatures reached and therefore the limited durability of the welding tools.

Previous research has already shown that it is possible to weld mild steel and other low to medium carbon ferrous alloys. Even high carbon steels and stainless steels can be welded successfully with a tungstenbased tool material. The emphasis of this review is to evaluate the feasibility of materials for the production of FSW tools for high strength steels [4-8].

\section{TOOL REQUIREMENTS}

The tools have to withstand severe conditions during the friction stir welding process. The heat generated during this process, causes high temperatures in the contact zone and also high temperature gradients. According to [9] the work material temperature is possibly increased to about $80 \%$ of its melting temperature. For HSLA steels, the temperature can thus reach $1100^{\circ} \mathrm{C}$.

To build up resistance against fatigue and fracture, a high fracture toughness of the tool is required. It is also important that the ductile to brittle transition temperature of the tool material is sufficiently low. Indeed, materials that are brittle at room temperature might fail during the initial plunge stage.

It is necessary that the tool's hardness and strength don't decrease much in these high temperature circumstances to ensure that tool deformation and wear are limited.

The thermal conductivity of the tool material is a measure for the rate of heat removal. It affects the temperature field, flow stress and the weld microstructure. A high thermal conductivity avoids the formation of hot spots on the tool and allows the use of a cooling mechanism to lower the temperature of the tool. However, high thermal conductivity causes an excessive removal of heat from the weld region which implies the need of higher welding forces [10].

To obtain a smooth weld surface, a low coefficient of friction between tool material and workpiece is required. From experience it is known that FSW of steel with pcBN results in a smooth welding surface [10].

It is favourable that the tool is chemically inert with respect to ferrous materials and corrosion resistant.

As the tool geometry plays an important role in the formation of the weld [11], it is profitable that the tool material is easy to machine. However to weld high strength steels, hard metals and ceramics are used and these materials are known to be rather difficult to machine. 
The main challenge for the industrial exploitation of FSW of steels is undoubtedly the development of a reliable, lasting and cost effective tool material and this is where the potential benefits of research could be large [12].

\section{CANDIDATE TOOL MATERIALS}

\subsection{Tungsten Carbide (WC)}

WC is a very strong material due to the covalent bonding between the $\mathrm{W}$ and $\mathrm{C}$ atoms. This bonding also leads to a high melting temperature of about $2900^{\circ} \mathrm{C}$ and a high hardness at room temperature up to $27 \mathrm{GPa}$. Tungsten carbide however is brittle in nature with a fracture toughness between 2-4 MPa.m ${ }^{1 / 2}$.

To enhance different mechanical properties and sinterability, a second phase material is added. In the following, different second phase materials are discussed, in particular their advantages and disadvantages for use in FSW.

\subsubsection{Metallic binder}

The addition of cobalt leads to an excellent wettability and adhesion with the tungsten carbide. This facilitates sintering and increases strength and toughness considerably. The hardness and wear resistance however are inversely proportional to the added cobalt content. The mechanical properties are strongly dependent on grain grade and added cobalt content as can be seen in Figure 1.
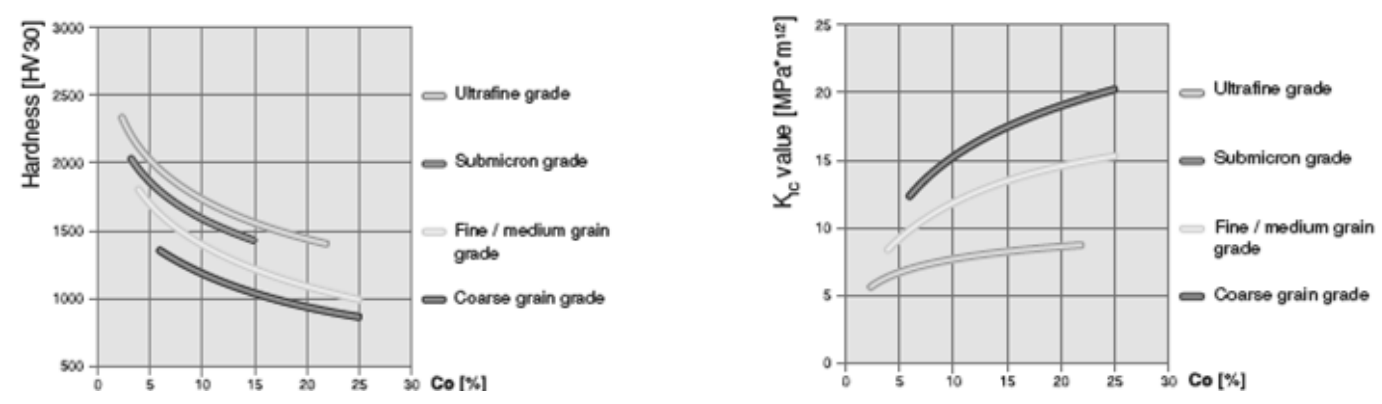

Figure 1: Hardness and fracture toughness of WC-Co with varying Cobalt content [13]

Experiments showed that the metallic binder is inferior to the WC in corrosive and elevated temperature applications [14]. At temperatures above $600^{\circ} \mathrm{C}$, a significant strength degradation is observed. This degradation is caused by high oxidation rates and the development of microstructural defects [15].

Figure 2 shows the softening of WC-Co at temperatures above $600^{\circ} \mathrm{C}$. Since temperatures up to $1000^{\circ} \mathrm{C}$ are common during friction stir welding, research is required to find other materials that maintain their properties at these high temperatures.

The advantages of using nickel instead of cobalt as binder are the improved corrosion and oxidation resistance [16-20]. WC-Ni is also favorable to use instead of WC-Co in applications where hot hardness and resistance against thermal cracking are essential $[16,17]$. However, the difference with WC-Co is not significant. Mechanical properties of WC-Ni with varying nickel content are presented in Figure 3.

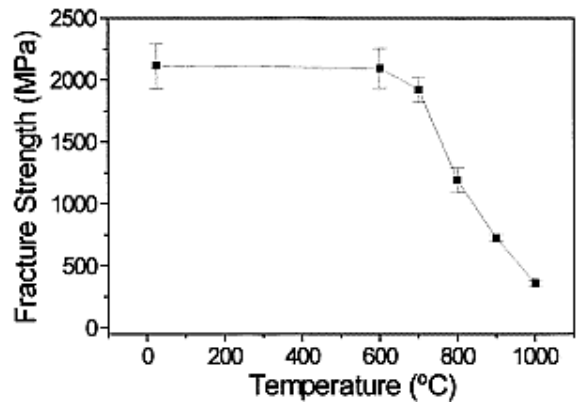

Figure 2. Fracture strength of WC-Co at high temperatures $[15,21]$

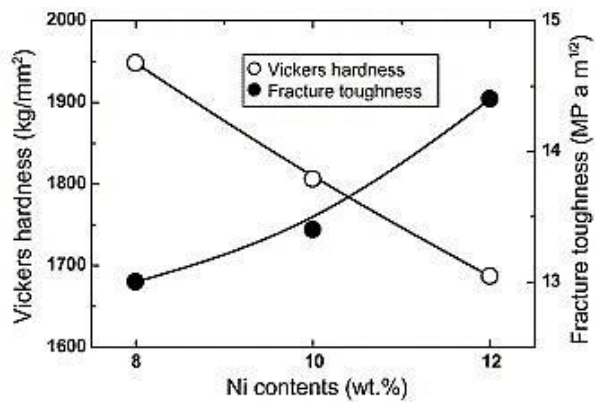

Figure 3. Hardness and fracture toughness of WC-Ni with varying Ni-content [19] 


\subsubsection{Ceramic binder}

The utilization of zirconia $\left(\mathrm{ZrO}_{2}\right)$ as a ceramic additive instead of a metallic binder is interesting because zirconia is an electrical and thermal isolator and does not soften at elevated temperatures. It is also not susceptible to electrochemical corrosion. The addition of zirconia to WC leads to an increase in fracture toughness due to transformation toughening and a small decrease in Vickers hardness [22].

Adding alumina $\left(\mathrm{Al}_{2} \mathrm{O}_{3}\right)$ results in a tool material that combines two opposite properties, high hardness and relatively high fracture toughness, which makes it very attractive for the use as cutting or welding tool [36]. Experiments showed that adding alumina has a remarkable influence on microstructure, the crack propagation path and the mechanical properties. With increasing content of $\mathrm{Al}_{2} \mathrm{O}_{3}$, the relative density increases while Vickers hardness and fracture toughness initially increase to their maximum values and then decrease [23]. Another study found apparently contrasting results as can be seen in Figure 4. They found that the addition of alumina results in a toughening effect, but the hardness decreases [14]. The difference in both studies indicates that the mechanical properties are not only dependent on alumina content but also on the production process and the properties of the different base materials.

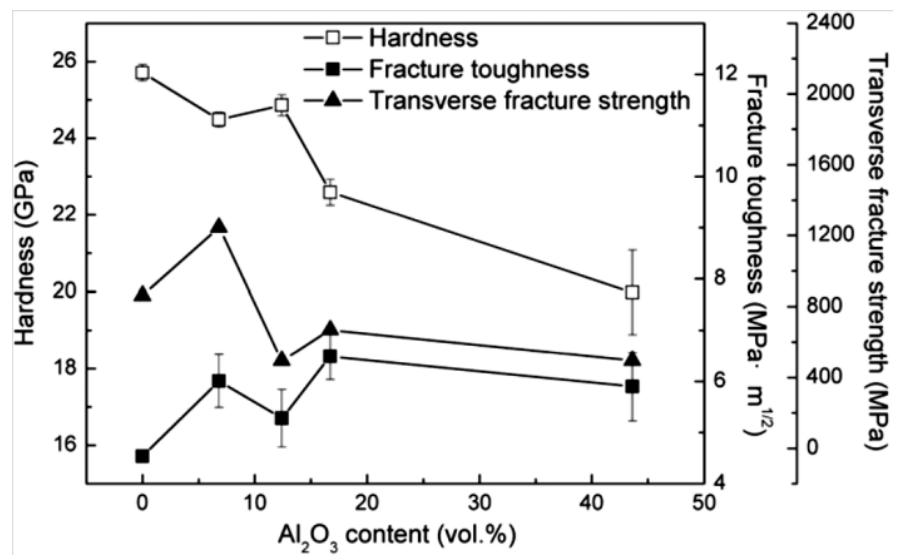

Figure 4. Mechanical properties of $\mathrm{WC}-\mathrm{Al}_{2} \mathrm{O}_{3}$ with varying alumina content [14]

The addition of titanium diboride $\left(\mathrm{TiB}_{2}\right)$ and some sintering additives to the pure WC leads to an increase in fracture toughness without decreasing the hardness significantly. Titanium diboride has very good mechanical properties. It has a high hardness around $32 \mathrm{GPa}$ and good corrosion and wear resistance [24].

Typical hardness and fracture toughness values of WC for the different ceramic additives are summarized in Table 1.

Table 1. Hardness and fracture toughness of WC with ceramic binder [14, 22, 23, 25]

\begin{tabular}{|c|l|l|l|}
\hline Ceramic additive & $\mathrm{ZrO}_{2}$ & $\mathrm{Al}_{2} \mathrm{O}_{3}$ & $\mathrm{TiB}_{2}$ \\
\hline Vickers Hardness [GPa] & $18-23$ & $16-25$ & $18-22$ \\
\hline Fracture toughness [MPa.m ${ }^{\mathbf{1 / 2}}$ ] & $4.9-6.2$ & $6-10$ & $6-8$ \\
\hline
\end{tabular}

\subsubsection{Cubic Boron Nitrides}

The addition of $\mathbf{c B N}$ particles to the WC-Co base material leads to a slight increase in hardness, a significant increase in fracture toughness and a moderate decrease of mechanical strength. The hardness increases due to the high hardness of the $\mathrm{CBN}$ particles. An increase in fracture toughness can be obtained due to the crack deflection effect of the cBN particles [26, 27].

The addition of $\mathrm{cBN}$ particles to the cemented carbides significantly decreases the sinterability. Therefore these composites are usually sintered by very costly techniques applying high temperatures and ultra-high pressures $(>5-8 \mathrm{GPa})$. The difficulty is the low stability of the high hardness cBN particles at high temperatures [26, 27].

Hardness and fracture toughness of WC-cBN are shown in Table 2. 
Table 2. Hardness and fracture toughness of WC-cBN [26]

\begin{tabular}{|c|c|c|c|}
\hline $\begin{array}{c}\text { Co content } \\
\text { (wt\%) }\end{array}$ & $\begin{array}{c}\text { cBN content } \\
\text { (vol\%) }\end{array}$ & HV [GPa] & $\begin{array}{c}\mathbf{K}_{\mathbf{I C}} \\
{\left[\text { [MPa.m }^{\mathbf{1 / 2}} \text { ] }\right.}\end{array}$ \\
\hline \multirow{2}{*}{1} & $30(\mathrm{~A})$ & 25.00 & 10.5 \\
\cline { 2 - 4 } & $30(\mathrm{~B})$ & 25.00 & - \\
\hline \multirow{3}{*}{5} & $50(\mathrm{~A})$ & 22.30 & 15.3 \\
\cline { 2 - 4 } & $50(\mathrm{~B})$ & 21.50 & 15.4 \\
\cline { 2 - 4 } & $50(\mathrm{C})$ & 21.50 & 14.7 \\
\hline 7 & $50(\mathrm{~A})$ & 22.30 & No cracks \\
\hline \multirow{2}{*}{10} & $50(\mathrm{~A})$ & 21.10 & No cracks \\
\hline
\end{tabular}

The letters $(A-C)$ represent different $c B N$ powder grades where $C$ represents the finest grade.

\subsection{Tungsten Rhenium (W-Re)}

The addition of rhenium to tungsten is very effective to lower the ductile to brittle transition temperature [28], which is defined as the temperature for $5 \%$ elongation. This temperature is $350 \mathrm{~K}$ when $25 \% \mathrm{Re}$ is added and is considerably lower than the other alloys. It is even possible to obtain a ductile to brittle transition temperature of $-50^{\circ} \mathrm{C}[10]$.

As can be seen in Figure 5, alloying tungsten with rhenium not only affects this transition temperature but also the ductility above the transition temperature. The ductility decreases with increasing rhenium content above $600 \mathrm{~K}$, the slope of the ductility-temperature curve also decreases.

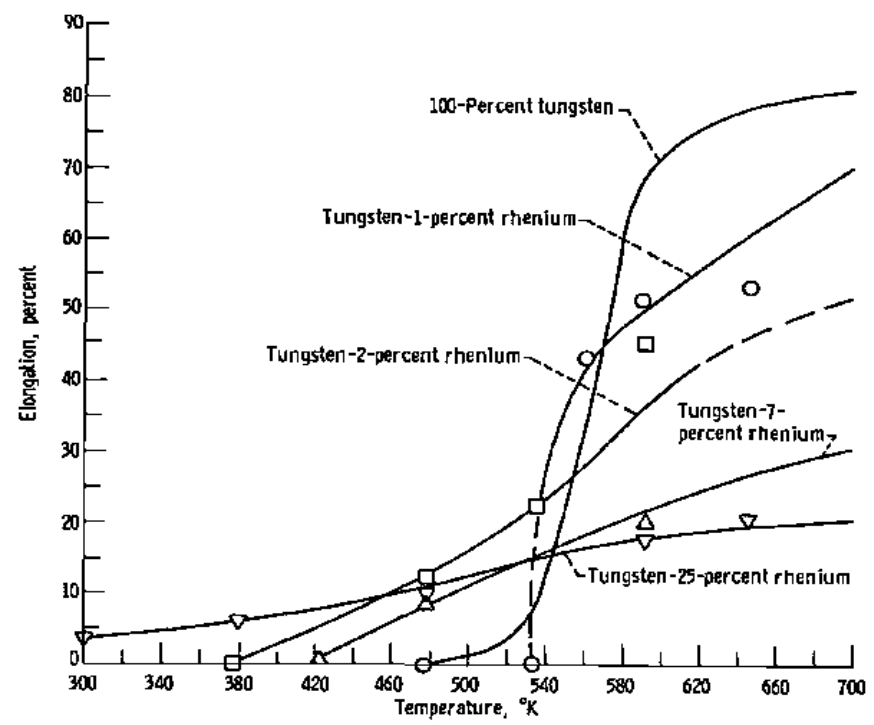

Figure 5. Effect of rhenium on ductility of arc-melted tungsten [28].

The yield strength and tensile strength are represented in Figure 6 as a function of temperature and rhenium content. The yield and ultimate tensile strength decreases with increasing temperature. By adding the component $\mathrm{HfC}$, a clear improvement of the strength is obtained. 

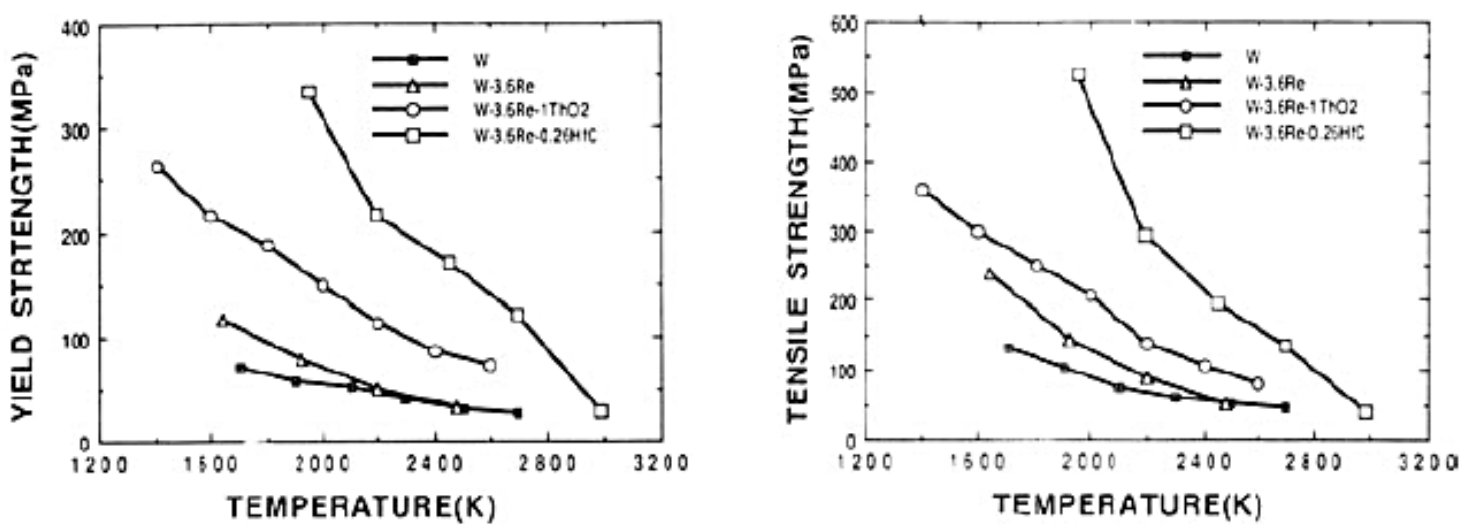

Figure 6. Yield strength and ultimate tensile strength of Tungsten Rhenium alloys as a function of temperature [29]

\subsection{Polycrystalline cubic boron nitride (pcBN)}

pcBN is a composite material consisting of small cBN particles bonded together in a skeletal matrix. $c B N$ is the second hardest material after diamond which results in a very high hardness of pcBN (>30GPa) [30].

As tool material, pcBN has to maintain this high hardness at high temperature. In Figure 7 the variation of hardness is plotted as a function of cBN content and temperature. There is an increase in hardness with $\mathrm{CBN}$ content. However in the temperature range $600-1000^{\circ} \mathrm{C}$ the rate of change of hardness is not significant. As expected, the hardness decreases with increasing temperature but the hardness at $1000^{\circ} \mathrm{C}$ is still higher than for many materials.

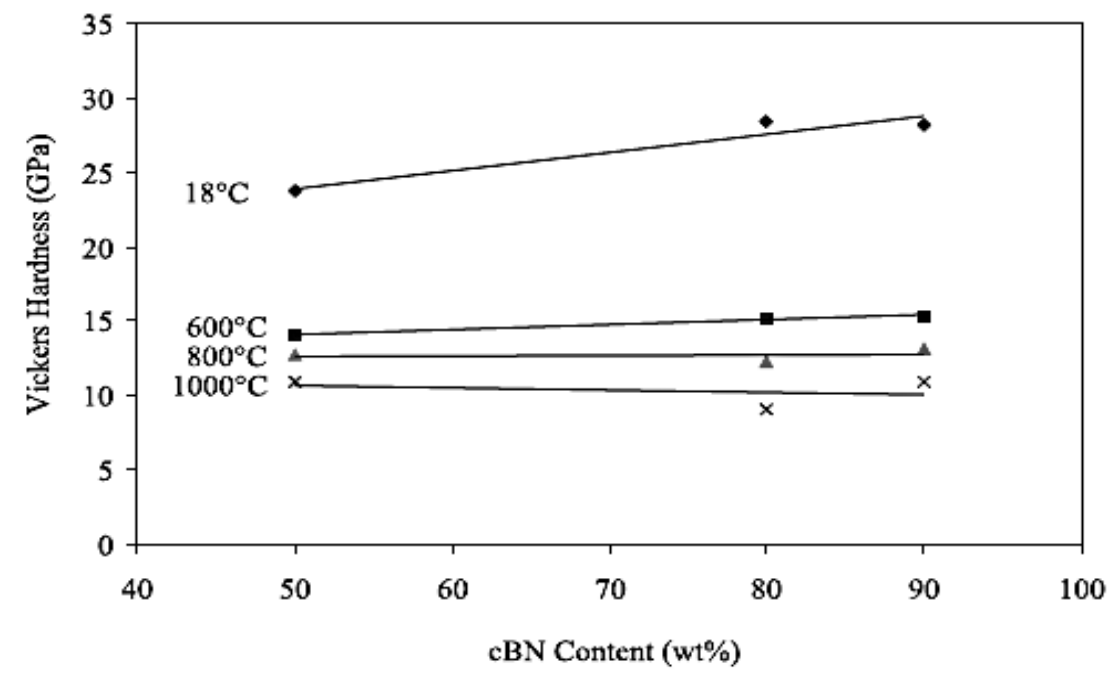

Figure 7. Variation in hardness with cBN content and temperature [31]

Another advantage of pcBN when used for the friction stir welding of steel is its low coefficient of friction which results in a smooth welding surface.

In general pcBN is used due to its very high hardness, wear resistance and thermal stability. It is inert to ferrous materials at temperatures above $1000^{\circ} \mathrm{C}$ while maintaining its strength [30]. On the other hand, pcBN is very expensive to manufacture and has a relatively low fracture toughness (4-6 MPa.m ${ }^{1 / 2}$ ), therefore pcBN has the tendency to fail during the initial plunge stage [32]. Generally, when higher fracture toughness is required, tools with high pcBN content $(80-90 \%)$ and a metallic binder are used. Tools with low pcBN content (45-65\%) and a ceramic binder are more resistant to diffusion wear [33].

\subsection{Ultrahigh temperature ceramics}

Transition metal diborides $\left(\mathrm{TiB}_{2}, \mathrm{ZrB}_{2}, \mathrm{HfB}_{2}\right.$, etc.) are commonly known as ultra-high temperature ceramics (UHTCs) as they possess melting temperatures above $3000^{\circ} \mathrm{C}$. 


\subsubsection{Zirconium diboride $\left(\mathrm{ZrB}_{2}\right)$}

The use of $\mathrm{ZrB}_{2}$ is still limited because of its very low fracture toughness and strength. To improve the mechanical properties, ceramic additives or a second phase with strengthening and toughening capabilities can be added. Another disadvantage of $\mathrm{ZrB}_{2}$ is the oxidation in air at elevated temperatures. It has been shown that the oxidation resistance of $\mathrm{ZrB}_{2}$ can be further enhanced by reacting it with up to $15 \% \mathrm{SiC}$ [34].

A comparison of the mechanical properties of $\mathrm{ZrB}_{2}$ as a function of $\mathrm{SiC}$ content is presented in Table 3. The specimens tested were sintered for 3 hours at a temperature of $2000^{\circ} \mathrm{C}$. There is also $5 \%$ carbon added based on SIC weight and $4 \% \mathrm{~B}_{4} \mathrm{C}$ based on $\mathrm{ZrB}_{2}$ weight.

Table 3. Comparison of mechanical properties of ZrB2 with 10, 20 and 30 vol\% SIC [35]

\begin{tabular}{|c|c|c|c|c|}
\hline $\begin{array}{c}\text { SiC volume } \\
\text { fraction [vol\%] }\end{array}$ & $\begin{array}{c}\text { Elastic Modulus } \\
\text { [GPa] }\end{array}$ & Hardness [GPa] & $\begin{array}{c}\text { Flexure strength } \\
\text { [MPa] }\end{array}$ & $\begin{array}{c}\text { Toughness } \\
\text { [MPa.m }{ }^{1 / 2} \text { ] }\end{array}$ \\
\hline 10 & $446 \pm 7$ & $15.3 \pm 1.2$ & $404 \pm 62$ & $3.1 \pm 0.1$ \\
\hline 20 & $474 \pm 7$ & $18.8 \pm 1.1$ & $463 \pm 53$ & $3.4 \pm 0.1$ \\
\hline 30 & $490 \pm 7$ & $22.4 \pm 0.7$ & $492 \pm 49$ & $3.5 \pm 0.3$ \\
\hline
\end{tabular}

The thermal conductivity of $\mathrm{ZrB}_{2}$ lies between $60-140 \mathrm{~W} \cdot \mathrm{m}^{-1} \mathrm{~K}^{-1}$ and unlike most ceramics $\mathrm{ZrB}_{2}$ has a good electrical conductivity and complex shaped parts can easily be made by electrical discharge machining [35, 36].

\subsubsection{Transition metal diborides $\left(\mathrm{TiB}_{2}\right)$ and boron carbide $\left(\mathrm{B}_{4} \mathrm{C}\right)$}

Looking at the mechanical and physical properties, $\mathbf{T i B}_{2}$ can be very attractive for friction stir welding applications. The hardness at room temperature varies between $2500-2700 \mathrm{HV}$ and the fracture toughness between $6-8 \mathrm{MPa} \cdot \mathrm{m}^{1 / 2}$. However, according to [37], $\mathrm{TiB}_{2}$ is difficult to sinter because of its covalent bonding nature, low self-diffusion coefficient and presence of an oxide layer $\left(\mathrm{TiO}_{2}\right.$ and $\left.\mathrm{B}_{2} \mathrm{O}_{3}\right)$ on the $\mathrm{TiB}_{2}$ powder surface. The use of metallic or non-metallic sinter additives is essential to enhance the sinterability of $\mathrm{TiB}_{2}$. However, the mechanical properties will also be affected with the additives [37].

Boron carbide $\left(\mathbf{B}_{4} \mathbf{C}\right)$ ceramics possess a very a high hardness (38-42 $\mathrm{GPa}$ ) and a high melting point (2370$2480^{\circ} \mathrm{C}$ ). It is a promising candidate for wear resistant components. However, the use of $\mathrm{B}_{4} \mathrm{C}$ is restricted because of a low fracture toughness $\left(<2.2 \mathrm{MPa} \cdot \mathrm{m}^{1 / 2}\right)$ and poor sinterability [38].

To improve the fracture toughness of $B_{4} C, T_{i} B_{2}-B_{4} C$ is formed. Since $T_{i} B_{2}$ and $B_{4} C$ have high hardness and high melting points, the composite can be used for advanced structural materials [38]. In Figure 8 the influence of the amount of $\mathrm{TiB}_{2}$ on fracture toughness is shown.

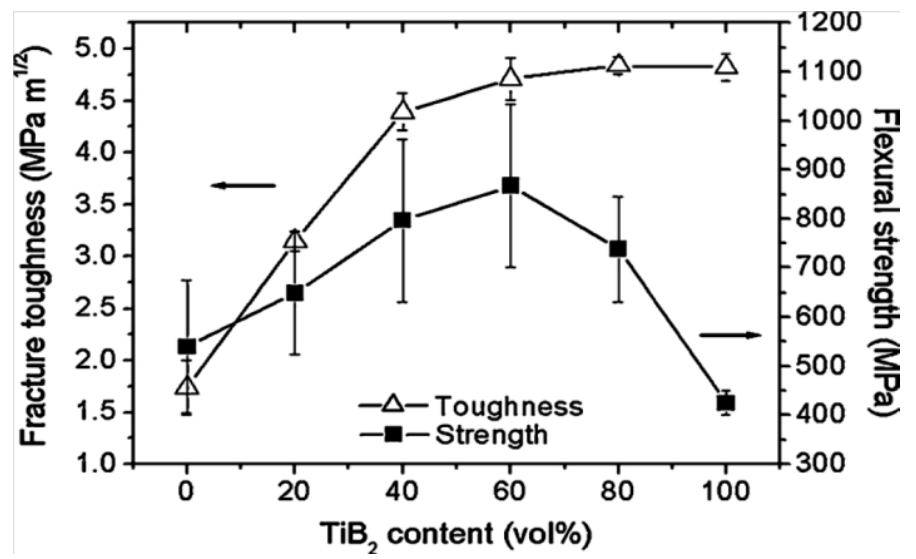

Figure 8. Influence of the amount of TiB2 on fracture toughness and flexural strength of $\mathrm{TiB}_{2}-\mathrm{B}_{4} \mathrm{C}$ [39]

\section{CONCLUSION}

The interest in the development of FSW of steel has grown the last decade. In comparison with FSW of low melting temperature materials, the requirements of the tools are more severe. Tungsten, tungsten carbide, pcBN and ultra-high temperature ceramics are candidate tool materials. Their properties, advantages and 
drawbacks have been discussed. Mechanical properties such as hardness and fracture toughness at ambient temperature are summarized in Table 4 . The behaviour of these materials at high temperatures however still needs a lot of investigation.

Table 4. Mechanical properties of the discussed materials at ambient temperature

\begin{tabular}{|c|c|c|c|c|}
\hline Material & Additive & $\begin{array}{l}\text { Hardness } \\
\text { [GPa] }\end{array}$ & $\begin{array}{c}\text { Fracture } \\
\text { toughness } \\
{\left[\mathrm{MPa}^{1 / 2}\right]}\end{array}$ & At high temperature? \\
\hline \multirow{6}{*}{ WC } & Co & $10-20$ & $5-20$ & Softening at temperatures above $600^{\circ} \mathrm{C}$ \\
\hline & $\mathrm{Ni}$ & $15-20$ & $10-15$ & Similar behaviour as with Co \\
\hline & $\mathrm{ZrO}_{2}$ & $18-23$ & $4.5-6.5$ & \multirow{3}{*}{$\begin{array}{c}\text { Unknown but ceramic binder is expected } \\
\text { to behave better at high temperatures } \\
\text { than a metallic one. }\end{array}$} \\
\hline & $\mathrm{Al}_{2} \mathrm{O}_{3}$ & $16-25$ & $6-10$ & \\
\hline & $\mathrm{TiB}_{2}$ & $18-22$ & $6-8$ & \\
\hline & $\mathrm{cBN}$ & $20-25$ & $10-15$ & cBN high temperature resistant \\
\hline W-Re & - & 7 & & unknown \\
\hline pcBN & - & $23-27$ & $4-6$ & Remains required hardness and strength \\
\hline $\mathrm{ZrB}_{2}$ & & $15-23$ & $3-4$ & \multirow{2}{*}{ Ultra high temperature ceramic } \\
\hline $\mathrm{TiB}_{2}$ & & $25-27$ & $6-8$ & \\
\hline
\end{tabular}

During this research, a test setup will be developed to simulate the tool conditions that appear during the FSW process. Different materials will be tested and their performance will be evaluated.

\section{REFERENCES}

[1] Mishra, R.S. and Z.Y. Ma, Friction stir welding and processing. Materials Science and Engineering: R: Reports, 2005. 50(1-2): p. 1-78.

[2] Park, S.H.C., Y.S. Sato, and H. Kokawa, Effect of micro-texture on fracture location in friction stir weld of Mg alloy AZ61 during tensile test. Scripta Materialia, 2003. 49(2): p. 161-166.

[3] Dawes, C.J. and W.M. Thomas, Friction stir process welds aluminum alloys. Welding Journal, 1996. 75(3): p. 41-45.

[4] Fujii, H., et al., Friction stir welding of carbon steels. Materials Science and Engineering: A, 2006. 429(1-2): p. 50-57.

[5] Chung, Y.D., et al., Friction stir welding of high carbon steel with excellent toughness and ductility. Scripta Materialia, 2010. 63(2): p. 223-226.

[6] Ueji, R., et al., Friction stir welding of ultrafine grained plain low-carbon steel formed by the martensite process. Materials Science and Engineering: A, 2006. 423(1-2): p. 324-330.

[7] Reynolds, A.P., et al., Structure, properties, and residual stress of 304L stainless steel friction stir welds. Scripta Materialia, 2003. 48(9): p. 1289-1294.

[8] Nandan, R., et al., Three-dimensional heat and material flow during friction stir welding of mild steel. Acta Materialia, 2007. 55(3): p. 883-895.

[9] Assidi, M., et al., Friction model for friction stir welding process simulation: Calibrations from welding experiments. International Journal of Machine Tools \& Manufacture, 2010. 50(2): p. 143155.

[10] Rai, R., et al., Review: friction stir welding tools. Science and Technology of Welding and Joining, 2011. 16(4): p. 325-342.

[11] Nandan, R., T. DebRoy, and H. Bhadeshia, Recent advances in friction-stir welding - Process, weldment structure and properties. Progress in Materials Science, 2008. 53(6): p. 980-1023.

[12] Bhadeshia, H.K.D.H. and T. DebRoy, Critical assessment: friction stir welding of steels. Science and Technology of Welding and Joining, 2009. 14(3): p. 193-196.

[13] Ceratizit. Ceratizit catalogue. 18 novembre 2012]; Available from: http://www.ceratizit.com/4170B_ENG_HTML_ENG_HTML.php?lc=7\&entryld=1000313767_BS\&ex pandld $=1000313791$.

[14] Zheng, D.H., et al., Bulk WC-Al2O3 composites prepared by spark plasma sintering. International Journal of Refractory Metals \& Hard Materials, 2012. 30(1): p. 51-56. 
[15] Acchar, W., et al., Strength Degradation of a Tungsten Carbide-Cobalt Composite at Elevated Temperatures. Materials Characterization, 1999. 43(1): p. 27-32.

[16] K. Bonny, P.D.B., J. Vleugels, S. Huang, B. Lauwers, Tribological Characteristics of WC-Ni and WC-Co Cemented Carbide in Dry Reciprocating Sliding Contact. TRIBOLOGY TRANSACTIONS 52(4), 2009: p. 481-491.

[17] Wittmann, B., W.-D. Schubert, and B. Lux, WC grain growth and grain growth inhibition in nickel and iron binder hardmetals. International Journal of Refractory Metals and Hard Materials, 2002. 20(1): p. 51-60.

[18] Shatov, A.V., S.S. Ponomarev, and S.A. Firstov, Modeling the effect of flatter shape of WC crystals on the hardness of WC-Ni cemented carbides. International Journal of Refractory Metals and Hard Materials, 2009. 27(2): p. 198-212.

[19] Kim, H.-C., et al., Rapid sintering of ultrafine WC-Ni cermets. International Journal of Refractory Metals and Hard Materials, 2006. 24(6): p. 427-431.

[20] Bonny, K., et al., Influence of electrical discharge machining on sliding friction and wear of WC-Ni cemented carbide. Tribology International, 2010. 43(12): p. 2333-2344.

[21] Chapter Two: Literature Survey, in unknown. p. 24-61.

[22] Malek, O., et al., Processing of ultrafine ZrO2 toughened WC composites. Journal of the European Ceramic Society, 2009. 29(16): p. 3371-3378.

[23] Qu, H.X., et al., Microstructure and mechanical properties of hot-pressing sintered WC-x vol.\%Al2O3 composites. Materials Science and Engineering a-Structural Materials Properties Microstructure and Processing, 2012. 543: p. 96-103.

[24] Gu, M., et al., Improvements in mechanical properties of TiB2 ceramics tool materials by the dispersion of Al2O3 particles. Materials Science and Engineering: A, 2008. 486(1-2): p. 167-170.

[25] Song, J.P., et al., Effects of sintering additives on microstructure and mechanical properties of TiB2-WC ceramic-metal composite tool materials. International Journal of Refractory Metals \& Hard Materials, 2012. 30(1): p. 91-95.

[26] Martínez, V. and J. Echeberria, Hot Isostatic Pressing of Cubic Boron Nitride-Tungsten Carbide/Cobalt (cBN-WC/Co) Composites: Effect of cBN Particle Size and Some Processing Parameters on their Microstructure and Properties. Journal of the American Ceramic Society, 2007. 90(2): p. 415-424.

[27] Wang, B., et al., The Effect of cBN Additions on Densification, Microstructure and Properties of WC-Co Composites by Pulse Electric Current Sintering. Journal of the American Ceramic Society, 2012. 95(8): p. 2499-2503.

[28] Raffo, P.L., Yielding and fracture in tungsten and tungsten - rhenium alloys. Journal of the LessCommon Metals 1968: p. 133 - 149.

[29] Kwang S. Shin, A.L., Bor-Liang Chen and Dean L. Jacobson, High temperature properties of particle strengthened W-Re.

[30] FSW tool material developments for joining high melting temperature materials. p. 6.

[31] Harris, T.K., E.J. Brookes, and C.J. Taylor, The flow stress of PcBN cutting tool materials at high temperatures. International Journal of Refractory Metals \& Hard Materials, 2001. 19(4-6): p. 267273.

[32] Carl D. Sorensen, T.W.N., Scott M. Packer, Russel J. Steel, Innovative Technology Applications in FSW of High Softening Temperature Materials, in 5th Symposium2004.

[33] de Oliveira, A.J., A.E. Diniz, and D.J. Ursolino, Hard turning in continuous and interrupted cut with PCBN and whisker-reinforced cutting tools. Journal of Materials Processing Technology, 2009. 209(12-13): p. 5262-5270.

[34] Metals, A.S.f., Metals Handbook Ninth Edition - Volume 7 Powder Metallurgy. Ninth edition ed. 1984.

[35] Zhang, S.C., G.E. Hilmas, and W.G. Fahrenholtz, Mechanical properties of sintered ZrB2-SiC ceramics. Journal of the European Ceramic Society, 2011. 31(5): p. 893-901.

[36] Yuan, H., et al., Preparation and thermal conductivity characterization of ZrB2 porous ceramics fabricated by spark plasma sintering. International Journal of Refractory Metals and Hard Materials, (0).

[37] Raju, G.B., et al., Temperature dependent hardness and strength properties of TiB2 with TiSi2 sinter-aid. Journal of the European Ceramic Society, 2009. 29(10): p. 2119-2128.

[38] Yue, X.Y., et al., Synthesis and properties of hot pressed B4C-TiB2 ceramic composite. Materials Science and Engineering a-Structural Materials Properties Microstructure and Processing, 2010. 527(27-28): p. 7215-7219.

[39] Huang, S.G., et al., Microstructure and mechanical properties of pulsed electric current sintered B4C-TiB2 composites. Materials Science and Engineering a-Structural Materials Properties Microstructure and Processing, 2011. 528(3): p. 1302-1309. 